\title{
MACROPHAGE RESPONSE TO STAPHYLOCOCCAL BIOFILMS ON CROSSLINKED POLY(ETHYLENE) GLYCOL POLYMER COATINGS AND COMMON BIOMATERIALS IN VITRO
}

\author{
Isabel C. Saldarriaga Fernández ${ }^{1}$, Joana F. Da Silva Domingues ${ }^{1}$, Theo G. van Kooten ${ }^{1}$, Steve Metzger², \\ David W. Grainger ${ }^{3}$, Henk J. Busscher ${ }^{1}$ and Henny C. van der Mei ${ }^{1 *}$

\begin{abstract}
${ }^{1}$ Department of BioMedical Engineering, University Medical Center Groningen, and University of Groningen, Antonius Deusinglaan 1, 9713 AV Groningen, The Netherlands

${ }^{2}$ Accelr8 Technology Corporation, Denver, CO, USA

${ }^{3}$ Departments of Pharmaceutics and Pharmaceutical Chemistry, and Bioengineering, College of Pharmacy,
\end{abstract} \\ University of Utah, Salt Lake City, UT, USA
}

\begin{abstract}
Biomaterial-associated-infections (BAI) are serious clinical complications that threaten the longevity of implanted devices and lead to high morbidity and mortality. Poly(ethylene)glycol (PEG) coatings have been studied as a strategy to reduce the incidence of BAI by reducing protein deposition that promotes pathogen adhesion and growth on device surfaces. Despite their effectiveness to reduce protein adsorption and a hundred-fold reduction in bacterial adhesion, PEG-based coatings still facilitate weak bacterial adhesion that can form an initial basis for biofilms. Here, we describe a methodology enabling direct, quantitative and detailed qualitative in situ observation of macrophage morphology, migration and phagocytosis of bacteria. In vitro interaction of macrophages with Staphylococcus epidermidis 3399 adhering to commercial, crosslinked PEG-based coatings (OptiChem ${ }^{\circledR}$ ) was compared with fluorinated ethylene propylene, silicone rubber and glass. Adhesion, phagocytosis and migration were studied real-time in a parallel-plate-flow-chamber. Macrophages cultured on OptiChem ${ }^{\circledR}$ coatings showed enhanced migration and phagocytosis of bacteria compared to common biomaterials. Bacterial clearance per macrophage on both inert and reactive OptiChem $\AA$ coatings were about three times higher than on the common biomaterials studied, corresponding with up to $70 \%$ reduction in bacterial numbers on OptiChem $\AA$, whereas on the biomaterials less than $40 \%$ bacterial reduction was obtained. These findings show that bacterial clearance from cross-linked PEG-based coatings by macrophages is more effective than from common biomaterials, possibly resulting from weak adhesion of bacteria on Optichem ${ }^{\circledR}$. Moreover, macrophages exhibit higher mobility on Optichem ${ }^{\circledR}$ retaining an improved capability to clear bacteria from larger areas than from other common biomaterials, where they appear more immobilized.
\end{abstract}

Keywords: S. epidermidis, macrophages J774, cross-linked poly(ethylene) glycol, polymer coatings, biomaterial associated infection, bacteria, adhesion.

*Address for correspondence:

Henny C. van der Mei

Department of Biomedical Engineering FB-40

University Medical Center Groningen and University of Groningen

P.O. Box 196, 9700 AD Groningen

The Netherlands
Telephone Number: 31503633140

FAX Number: 31503633159

E-mail: h.c.van.der.mei@med.umcg.nl

\section{Introduction}

Placement of indwelling medical devices into the human body to support and restore function has become common practice in modern medicine with reasonable overall success rates. In 2006, for instance, nearly 800,000 primary total hip and knee arthroplasties were performed in the United States alone (Del Pozo and Patel, 2009). Biomaterial-associated infections (BAI) and adverse interactions between the indwelling device and the surrounding tissues and cells are, however, factors that threaten the device's functionality and longevity (Gristina, 1987). BAI, although of relatively low incidence, represents a serious complication of extensive significance, with related high morbidity and mortality rates, as well as with high associated health care costs. Despite advances in surgical techniques, peri-operative contamination remains the most common route for the infection of biomaterial devices (Busscher et al., 2009). Microorganisms, usually sourced from the patient's skin, adhere to the implant surface, colonize it and rapidly form biofilms (Knobben et al., 2006). Generally, microorganisms embedded in biofilms are much less susceptible to antimicrobial treatments (Stewart and Costerton, 2001) and host immune mechanisms than planktonic organisms and hence, infection usually persists until the device is removed.

BAI pathogenesis depends on many factors, such as implant site, device type and the patient's general health status, but also on the interaction between the biomaterial surface, the host's immune system and the infecting pathogen (Del Pozo and Patel, 2009; Kwakman et al., 2006). Following biomaterial implantation, tissue trauma and injury trigger a cascade of physiological events that activate the immune system (Xia and Triffitt, 2006). Neutrophils and monocytes/macrophages are the major host inflammatory cell populations that arrive within minutes to hours at the implant site (Anderson, 2004; Xia and Triffitt, 2006). In contrast to neutrophils that may disappear within hours, macrophages increase in numbers over time and remain at the implant surface for several weeks depending on the severity of the injury (Anderson, 2004). Macrophages orchestrate the host inflammation process and eventual foreign body reactions, but are also 
an important active component in pathogen clearance. During bacterial infection in vivo, macrophages adhere to the infected tissue and detect bacteria via cell surface receptors (Xia and Triffitt, 2006). After recognition and pathogen attachment, macrophages engulf bacteria (phagocytosis) and activate cellular functions such as proliferation, secretion of proteins and cytokines, and respiratory bursts to destroy phagocytosed bacteria and recruit other cells from the adaptive immune system, as for example $\mathrm{T}$ and B lymphocytes (Berton and Lowell, 1999). However, the presence of a biomaterial affects the immune system's response to bacterial infection, and the biomaterial surface chemistry can stimulate (Xia and Triffitt, 2006) or reduce macrophage adhesion, phagocytic activity and migration (Henke et al., 1997; Boelens et al., 2000). Therefore, macrophage-biomaterial-bacteria interactions are crucial factors influencing pathogenesis of BAI (Boelens et al., 2000).

Poly(ethylene) glycol (PEG) has been promoted as an infection-resistant biomaterial coating due to low protein adsorption and hundred-fold reductions in adhering bacteria with respect to common biomaterials (Norde and Gage, 2004; Saldarriaga Fernandez et al., 2007; Nejadnik et al., 2008a,b). Nonetheless, this performance does not prevent the formation of weakly adhering, more mature biofilms (Nejadnik et al., 2008a; Saldarriaga Fernandez et al., 2010). Currently, it is unknown how macrophages deal with the few bacteria adhering to PEG-based coatings. Therefore, the aim of this study was to investigate the in vitro response of macrophages to Staphylococcus epidermidis adhering to a fully characterized commercial, multi-component crosslinked PEG-based polymer coating (OptiChem ${ }^{\circledR}$, Accelr8 Technology Corp., Denver, CO, USA) and to compare this with the response of the macrophages on common biomaterials such as fluorinated ethylene propylene (FEP) and silicone rubber. Glass was included since it acted as the substratum for the polymer coating and is a hydrophilic material, unlike FEP and silicone rubber. For convenience however, glass will be mentioned in this manuscript under the denominator "common biomaterials", as opposed to PEG-based polymer coatings.

\section{Materials and Methods}

\section{Substrata}

OptiChem ${ }^{\circledR}$-coated glass slides (Accelr8 Technology, now commercially available as Schott-Nexterion ${ }^{\mathrm{TM}}$ Slide H) were supplied by Accelr8 Technology Corporation. OptiChem ${ }^{\circledR}$ is a multi-component, cross-linked transparent and robust polymer coating, having PEG as its active component. The surface coating has an amine-reactive (i.e., an NHS active ester) terminal chemical functionality to allow specific immobilization of biomolecules. The NHS chemistry can also be deactivated to provide a surface with very low, nonspecific binding of biological molecules (Mao et al., 2005; Harbers et al., 2007; Takahashi et al., 2008). Extensive surface chemistry and analytical details regarding the coating and its bio-immobilization properties have been published (Mao et al., 2005; Harbers et al., 2007; Takahashi et al., 2008).

OptiChem ${ }^{\circledR}$ was applied on optical-grade glass slides by spin coating and curing. Slides were stored at $-20^{\circ} \mathrm{C}$ until use. Half of the coated slides were deactivated by quenching the NHS surface groups ("inert Optichem ${ }^{\circledR}$ ") using hydroxyethylamine (Harbers et al., 2007). The remaining slides were used in their NHS-reactive form, denoted here as "reactive OptiChem ${ }^{\circledR}$ ". Macrophage activity was also evaluated on FEP, silicone rubber and glass. FEP, silicone rubber and glass slides were cleaned in 2\% RBS 35 detergent solution (Omnilabo International, Breda, The Netherlands) under sonication and rinsed with demineralized water, submerged in methanol, washed with water again and finally with demineralized water. All samples were sterilized in $70 \%$ ethanol for $10 \mathrm{~min}$ and rinsed with sterile, demineralized water and finally with sterile phosphate buffered saline (PBS, $10 \mathrm{mM}$ potassium phosphate, $150 \mathrm{mM} \mathrm{NaCl}, \mathrm{pH}$ 6.8).

\section{Bacterial strain and growth conditions}

S. epidermidis 3399 is a clinical isolate from the skin and was used because skin-derived organisms like $S$. epidermidis are often involved in peri-operative contamination of biomaterial implant surfaces. The staphylococcus was first grown aerobically overnight at $37^{\circ} \mathrm{C}$ on blood agar plates from a frozen stock. The plates were kept at $4^{\circ} \mathrm{C}$, never longer than 2 weeks. One colony was used to inoculate $10 \mathrm{~mL}$ of tryptone soya broth (TSB, OXOID, Basingstoke, UK), which was incubated for $24 \mathrm{~h}$ at $37^{\circ} \mathrm{C}$ and used to inoculate a second culture in $200 \mathrm{~mL}$ TSB. Bacteria were harvested after overnight growth by centrifugation $\left(5 \mathrm{~min}\right.$ at $5000 \mathrm{~g}$ at $\left.10^{\circ} \mathrm{C}\right)$ and washed twice with sterile PBS. Bacteria were resuspended in sterile PBS to a concentration of $3 \times 10^{8}$ bacteria $/ \mathrm{mL}$.

\section{Cell culture conditions}

J774 mouse macrophages were grown in tissue culture polystyrene (TCPS) flasks (Greiner Bio-One, Frickenhausen, Germany), and maintained in Dulbecco's modified Eagle's medium (DMEM) supplemented with 4.5g/L D-glucose, pyruvate, and $10 \%$ fetal bovine serum (DMEM $+10 \% \mathrm{FBS}$ ) at $37^{\circ} \mathrm{C}$ in a humidified atmosphere of $5 \% \mathrm{CO}_{2}$. Cells were passaged every four days at 70 $80 \%$ confluency by scraping. The cells were passaged up to a maximum of seven times.

\section{J774 morphology, migration and phagocytic activity}

Macrophage morphology, migration and phagocytic activity on the crosslinked PEG-based coatings and the different common biomaterials were assessed using realtime in situ image analysis in a parallel plate flow chamber with a CCD camera (Basler, Ahrensburg, Germany) mounted on a phase-contrast microscope (Olympus BH2; Olympus, Tokyo, Japan) (for a detailed description of the system, see Busscher et al., 2006). Assays were performed on the bottom plate of the flow chamber containing the substrata under study. The system was first filled with sterile PBS to remove air-bubbles from the tubing and chamber, and perfused for 30 min with a laminar 

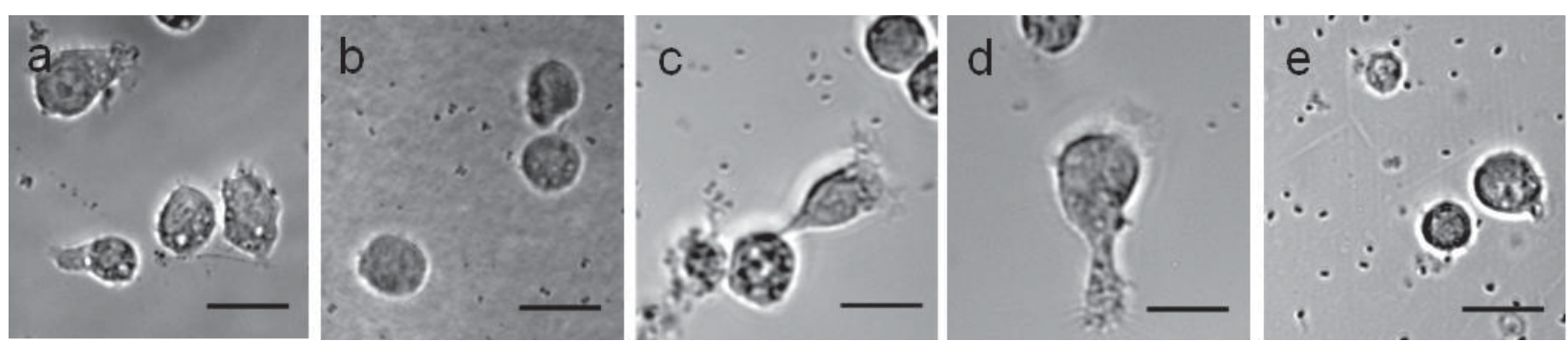

Fig. 1. Phase-contrast microscopic images showing the different morphologies of macrophages adhering to different cross-linked PEG-based coatings and common biomaterials in the presence of S. epidermidis 3399 in serum-containing culture media in the flow chamber. (a) FEP, (b) Silicone rubber, (c) Inert OptiChem ${ }^{\circledR}$, (d) Reactive OptiChem ${ }^{\circledR}$, and (e) Glass. The bar denotes $20 \mu \mathrm{m}$.

flow of $1.5 \mathrm{~mL} / \mathrm{min}$, corresponding to a wall shear rate of $11 \mathrm{~s}^{-1}$. Then, flow was switched to bacterial suspension in PBS that circulated at the same flow rate until the density of adhering bacteria had reached on average $4.2 \times 10^{5}$ bacteria $/ \mathrm{cm}^{2}$ on all substrata, as evaluated real-time with the image analysis system. Subsequently, the suspension was switched once more to sterile PBS to remove unbound bacteria from the system, which did not remove any adhering bacteria as could be experimentally established by virtue of the use of real-time imaging, since the flow rate stayed the same and no air-liquid interface was involved. The flow chamber was warmed up to $37^{\circ} \mathrm{C}$. Then, a macrophage suspension consisting of $7.5 \times 10^{5}$ cells $/ \mathrm{mL}$ in DMEM $+10 \%$ FBS was introduced into the system. Once the entire volume of buffer inside the chamber was replaced by the cell suspension, flow was stopped. Images were collected throughout the assay for $120 \mathrm{~min}$ at $1 \mathrm{~min}$ intervals. Phagocytic activity was determined by comparing the number of bacteria adhering per $\mathrm{cm}^{2}$ on the substrata at different time intervals. In addition, the difference between the initial numbers of bacteria adhering to the substratum prior to exposure to macrophages and the final bacterial density after $120 \mathrm{~min}$ exposure to the macrophages was calculated to determine the number of bacteria ingested per adherent macrophage. Bacterial growth during 120 min phagocytic activity was minimal in DMEM $+10 \%$ FBS and therefore neglected in these calculations.

\section{Results}

\section{Macrophage morphology}

Phase contrast images of cultured J774 murine macrophages interacting with bacteria adhering to crosslinked PEG-based coatings and the different common biomaterials in DMEM $+10 \%$ FBS are shown in Fig. 1 . Macrophages adhering to common biomaterials maintain a more spherical shape throughout the experiment, while those interacting with inert and reactive OptiChem ${ }^{\circledR}$ acquire a more elongated form increasing the contact area with the surface.

\section{Macrophage migration and phagocytic activity}

Macrophage activity was assessed microscopically in realtime. The number of macrophages adhering per $\mathrm{cm}^{2}$ on each substratum is presented in Table 1 . $\mathrm{J} 774$ cell migration and phagocytosis of bacteria on glass, inert and reactive
OptiChem ${ }^{\circledR}$ in the presence of adhering staphylococci are shown in Fig. 2. Macrophages adhering to common biomaterials are immobilized to the substratum and their migration is restricted to a few $\mu \mathrm{ms}$. Consequently, macrophages only phagocytose bacteria attached in their close surroundings via the projection of pseudopodia. In contrast, macrophages adhering on inert and reactive OptiChem $\AA$ coatings are more mobile, migrating relatively freely over the substratum towards adherent staphylococci. Time-lapse videos of macrophage migration and phagocytosis of $S$. epidermidis on the different substrata are available in the supporting information.

Under sterile operating conditions, the number of bacteria-carrying particles that fall on an open wound varies between $10^{2}$ and $10^{5}$ per $\mathrm{cm}^{2}$ (Fitzgerald, 1979; Oakes and Wood, 1986; Nelson, 1979). In this study, the initial bacterial density on all substrata was $4.2 \pm 0.9 \times 10^{5}$ per $\mathrm{cm}^{2}$ before macrophages were added into the system. The number of bacteria on the surface can thus be considered reasonably close to a clinically relevant situation of peri-operative contamination. After exposure to macrophages, the numbers of adhering staphylococci decreased significantly. Fig. 3 shows the percentage of bacteria left adhering on the surface as a function of exposure time to macrophages. Bacterial clearance per macrophage on inert and reactive OptiChem ${ }^{\circledR}$ coatings was on average three times higher than on the common biomaterials (see Table 1).

Table 1. Numbers of $S$. epidermidis remaining adherent on the surface per unit surface area after exposure to macrophages $\left(\mathrm{N}_{2 \mathrm{~h}}\right)$ for $120 \mathrm{~min}$, together with the numbers of macrophages per unit surface area and the number of staphylococci taken per macrophage for the five substrata involved in this study. The initial number of adhering staphylococci prior to exposure to macrophages was on average $4.2 \times 10^{5} \mathrm{~cm}^{-2}$, as determined during an experiment using real-time in situ observation. SD over six images per substratum surface.

\begin{tabular}{|l|c|c|c|}
\hline Substratum & $\begin{array}{c}\mathbf{N}_{\mathbf{2 h}} \\
\left(\mathbf{1 0}^{\mathbf{5}} / \mathbf{c m}^{\mathbf{2}}\right)\end{array}$ & $\begin{array}{c}\text { Macrophages } \\
\left(\mathbf{1 0}^{\mathbf{4}} / \mathbf{c m}^{\mathbf{2}}\right)\end{array}$ & Bacteria/macrophage \\
\hline FEP & $1.8 \pm 0.2$ & $6.3 \pm 0.5$ & $2.4 \pm 0.4$ \\
\hline Silicone rubber & $3.0 \pm 0.5$ & $4.1 \pm 0.8$ & $1.3 \pm 0.9$ \\
\hline Inert OptiChem ${ }^{\circledR}$ & $1.4 \pm 0.3$ & $4.3 \pm 0.5$ & $5.4 \pm 1.1$ \\
\hline Reactive OptiChem ${ }^{\circledR}$ & $1.1 \pm 0.3$ & $5.6 \pm 0.7$ & $6.9 \pm 1.0$ \\
\hline Glass & $4.1 \pm 0.3$ & $5.2 \pm 0.8$ & $2.8 \pm 0.6$ \\
\hline
\end{tabular}




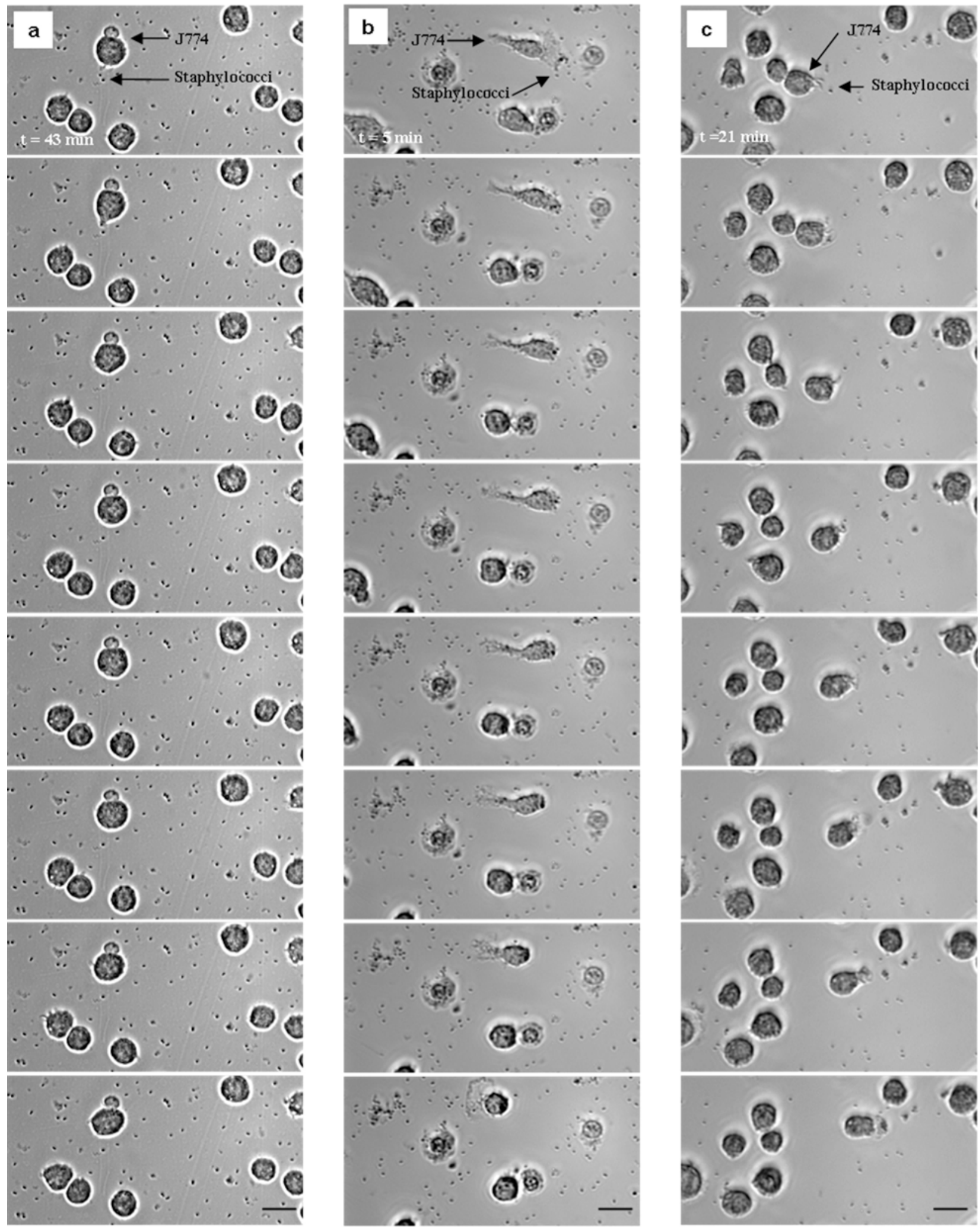

Fig. 2. Time-lapse light micrographs of the migration and phagocytosis of S. epidermidis 3399 by murine macrophages in serum-containing culture media in the flow chamber on (a) glass, (b) inert OptiChem $\AA$, and (c) reactive OptiChem ${ }^{\circledR}$. The interval between the micrographs is $2 \mathrm{~min}$, increasing from top to bottom. " $\mathrm{t}$ " denotes the time of exposure to macrophages. The bar denotes $20 \mu \mathrm{m}$. See supplementary information for video time-lapse files of macrophage real-time migration and phagocytosis. 


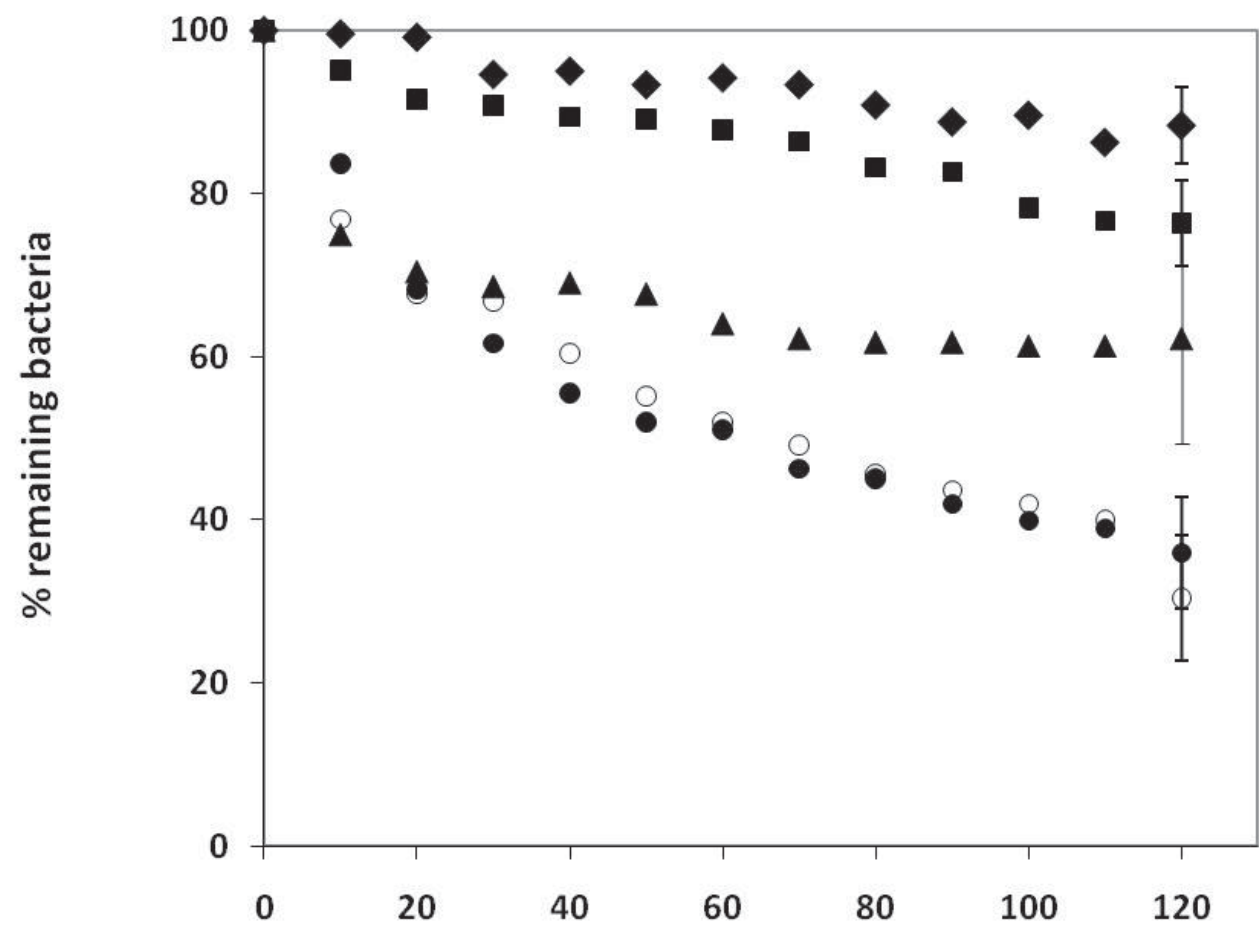

\section{Time ( $\min )$}

Fig. 3. Percentage of adhering S. epidermidis 3399 remaining on cross-linked PEG-based coatings and the various common biomaterials surfaces after exposure to macrophages for $120 \mathrm{~min}$ in serum-containing cell culture media with respect to their initial adherent density $\left(4.2 \times 10^{5} \mathrm{~cm}^{-2}\right)$ on: FEP $(\Delta)$, Silicone rubber $(\diamond)$, Inert OptiChem ${ }^{\circledR}$ $(\mathrm{O})$, Reactive OptiChem ${ }^{\circledR}(\bullet)$, and Glass $(\boldsymbol{\square})$. Error bars represent the standard deviation over six images.

\section{Discussion}

Macrophages are primary infiltrating immune system cells responding rapidly to wounding and implanted biomaterials, and are directly involved in the host inflammatory and foreign body response as well as in the defense against infectious pathogens. Macrophages adhere to device surfaces and remain at the implant-tissue interface for several days to realize their functions. Hence, the interaction between macrophages and bacterially contaminated biomaterials is crucial in the development of BAI (Boelens et al., 2000; Anderson, 2004). A mature biofilm is less likely to form if macrophages are able to remove and destroy microorganisms adhering on an implanted device. The response of macrophages to surfaces modified with PEG-based coatings has been assessed by others (Lynn et al., 2010; Schmidt and Kao, 2007; Jenney and Anderson, 1999), but never on bacterially contaminated biomaterial surfaces as done here. Our study showed that macrophages phagocytosis of bacteria adhering on inert and reactive OptiChem ${ }^{\circledR}$ was similar for both coatings, but on average three times higher than on the common biomaterials included in this study. This difference and elevated phagocytic activity of macrophages to S. epidermidis adhering on cross-linked PEG-based coatings is attributed to an almost unlimited macrophage mobility on the PEG-based coating compared to common biomaterials. On Optichem ${ }^{\circledR}$, macrophages reduced the numbers of adhering staphylococci by approximately $70 \%$ over a $2 \mathrm{~h}$ time period, as shown in Fig. 3. There are no comparative data available in the literature to determine whether this is a high or low phagocytosis efficiency. In a recent study (Wagner and Bryers, 2004) phagocytosis of S. epidermidis and Pseudomonas aeruginosa on PEGgraft-polyacrylate (PEG-g-PA) co-polymers has been studied. However, macrophages were allowed to adhere to the surface before bacteria were incorporated into the system, which is an entirely different model situation than our peri-operative model.

The enhanced macrophage mobility and phagocytic activity on Optichem ${ }^{\circledR}$ coatings could result from weak cell-surface interactions between these cells and the PEGbased coatings, but also bacteria-surface interaction forces are important for effective phagocytosis. Adhesion forces between microorganisms and poly(ethylene) oxide (PEO) brush coatings have been assessed using atomic force microscopy (Roosjen et al., 2006) and found to be up to 10 times smaller for various $P$. aeruginosa strains on a PEO brush than on bare glass. Incremental increases in shear rate in a parallel plate flow chamber also indicated that the adhesion strength of $S$. epidermidis and Staphylococcus aureus is decreased on PEO-coated silicone rubber. More than $85 \%$ of these bacteria could be sheared off from the PEO brush coating whereas up to $10 \%$ of adherent bacteria could be stimulated to detach from hydrophobic silicone rubber (Nejadnik et al., 2008b). Analogous to bacterial interactions with polymer brush coatings, macrophages adhering to OptiChem ${ }^{\circledR}$ coatings 
may be expected to experience weak adhesion forces as well, allowing them to move freely over the substratum towards adhering bacteria. Low adsorption of serum proteins on PEG-based surfaces, and specifically for OptiChem ${ }^{\circledR}$ coatings (Harbers et al., 2007) produces poor cell adhesion (Harbers et al., 2007; Takahashi et al., 2008). Macrophage-surface interactions depend less on cell matrix-type adhesive proteins in contrast to other cell types (Godek et al., 2009), and macrophage surface mobility is increased without a substantial surface-adsorbed protein layer. This occurs on both the inactivated (inert) PEG surface as well as that retaining the NHS-reactive immobilizing chemistry. Weak interactions between adhering bacteria and OptiChem ${ }^{\circledR}$ coatings, as described above, may also help facilitate more efficient macrophage phagocytosis from these surfaces. This is an advantage, as phagocyte-mediated clearance of surface-adhered bacteria is more difficult for macrophages than their clearance of planktonic bacteria (Leid, 2009).

In vivo, the interaction between proteins, pathogens and the host defense cells at the biomaterial-tissue interface is a complex process where each may contribute to bacterial survival and persistence on biomaterials and in adjacent tissues (Gristina, 1987; Boelens et al., 2000). Host defense functions are suggested to be affected in the presence of an infected biomaterial, for example, by diminishing host phagocytic activities (Henke et al., 1997; Kaplan et al., 1992; Boelens et al., 2000). We demonstrate that macrophages can phagocytose adhering bacteria more effectively on PEG-based coatings. Although macrophages are not the only cell type present at the interface in vivo, these results for macrophages are relevant, in that macrophages remain at the implanted biomaterial surface for longer periods of time than other cells (Anderson, 2004). Also an important factor in the persistence of BAI is bacterial survival within macrophages once ingested. This intra-phagocyte survival mechanism is both pathogen and substratum-dependent (Boelens et al., 2000). That such bacterial survival within macrophages is favored on OptiChem ${ }^{\circledR}$ coatings was not the focus of this study and should be elucidated.

\section{Conclusions}

We introduced a novel in vitro methodology to enable direct, quantitative and detailed qualitative in situ observations of macrophage adherent morphology, migration and engulfment of surface-resident bacteria. In the current study, we employed this methodology to compare macrophage clearance of adhering staphylococci from cross-linked PEG-based coatings and different common biomaterials, including glass. Substratum surfaces were first contaminated with bacteria prior to exposure to cultured macrophages in serum-based media to mimic perioperative bacterial contamination conditions. Macrophages on cross-linked PEG-based coatings exhibited enhanced cell mobility compared to the mobility on FEP, silicone rubber and glass, likely due to weak macrophage-surface interaction forces arising from strongly hydrated, low protein-adsorbing cross-linked PEG-based coatings. This greater intrinsic cell mobility and associated weak bacterial-surface adhesion forces facilitated higher phagocytosis on the PEG surfaces. Macrophage-mediated bacterial clearance was about three times more effective on the multi-component cross-linked PEG-based coatings (OptiChem ${ }^{\circledR}$ ) than on the common biomaterials included in this study, irrespective whether the surface was the inactivated or reactive NHS-derivatized PEG-based coating.

\section{Supporting Information}

Time-lapse videos of $\mathbf{J} 774$ macrophages migrating towards Staphylococcus epidermidis 3399 and their phagocytic activity on glass and OptiChem ${ }^{\circledR}$ coated glass are shown in the Supporting Information on this journal's electronic publication resources page on their website.

\section{References}

Anderson JM (2004) Biomaterials Science. An Introduction to Materials in Medicine. Elsevier, San Diego, CA, pp 296-304.

Berton G, Lowell CA (1999) Integrin signalling in neuthrophils and macrophages. Cell Signal 11: 621635 .

Boelens JJ, Dankert J, Murk JL, Weening JJ, van der Poll T, Dingemans KP, Koole L, Laman JD, Zaat SAJ (2000) Biomaterial-associated persistence of Staphylococcus epidermidis in pericatheter macrophages. J Infect Dis 181: 1337-1349.

Busscher HJ, Van der Mei HC (2006) Microbial adhesion in flow displacement systems. Clin Microbiol Rev 19: 127-141.

Busscher HJ, Ploeg RJ, Van der Mei HC (2009) Snapshot: biofilms and biomaterials; mechanisms of medical device related infections. Biomaterials 25: 42474248.

Del Pozo JL, Patel R (2009) Infection associated with prosthetic joints. N Engl J Med 361: 787-794.

Fitzgerald RH (1979) Microbiologic environment of the conventional operating-room. Colloids Surf B Biointerfaces 19: 127-141.

Godek ML, Michel R, Chamberlain LM, Castner DG, Grainger DW (2009) Adsorbed serum albumin is permissive to macrophage attachment to perfluorocarbon polymer surfaces in culture. J Biomed Mater Res A 88: 503-519.

Gristina AG (1987) Biomaterial-centered infection: microbial adhesion versus tissue integration. Science 237: 1588-1595.

Harbers GM, Emoto K, Greef C, Metzger SW, Woodward HN, Mascali JJ, Grainger DW, Lochhead MJ (2007) Functionalized poly(ethylene glycol)-based bioassay surface chemistry that facilitates bioimmobilization and inhibits nonspecific protein, bacterial, and mammalian cell adhesion. Chem Mater 19: 4405-4414.

Henke PK, Bergamini TM, Brittian KR, Polk HC Jr (1997) Prostaglandin E2 modulates monocyte MHC-II (Ia) suppression in biomaterial infection. J Surg Res 69: 372378. 
Jenney CR, Anderson JM (1999) Effects of surfacecoupled polyethylene oxide on human macrophage adhesion and foreign body giant cell formation in vitro. $\mathrm{J}$ Biomed Mater Res 44: 206-216.

Kaplan SS, Basford RE, Mora E, Jeong MH, Simmons RL (1992) Biomaterial-induced alterations of neutrophil superoxide production. J Biomed Mater Res 26: 10391051.

Knobben BAS, Engelsma Y, Neut D, Van der Mei HC, Busscher HJ, Van Horn JR (2006) Intraoperative contamination influences wound discharge and periprosthetic infection. Clin Orthop Relat Res 452: 236241.

Kwakman PH, Te Velde AA, Vandenbroucke-Grauls CM, Van Deventer SJ, Zaat SA (2006) Treatment and prevention of Staphylococcus epidermidis experimental biomaterial-associated infection by bactericidal peptide 2 . Antimicrob Agents Chemother 50: 3977-3983.

Leid JG (2009) Bacterial biofilms resist key host defenses. Microbe 4: 66-70.

Lynn AD, Kyriakides TR, Bryant SJ (2010) Characterization of the in vitro macrophage response and in vivo host response to poly(ethylene glycol)-based hydrogels. J Biomed Mater Res A 93: 941-953.

Mao G, Metzger S, Lochhead MJ (2005) US patent 6,844,028, 2005.

Nejadnik MR, Van der Mei HC, Norde W, Busscher HJ (2008a) Bacterial adhesion and growth on a polymer brush-coating. Biomaterials 29: 4117-4121.

Nejadnik MR, Van der Mei HC, Busscher HJ, Norde W (2008b) Determination of the shear force at the balance between bacterial attachment and detachment in weakadherence systems, using a flow displacement chamber. Appl Environ Microbiol 74: 916-919.

Nelson CL (1979) Environmental bacteriology in the unidirectional (horizontal) operating room. Arch Surg 114: 778-782.

Norde W, Gage D (2004) Interaction of bovine serum albumin and human blood plasma with PEO-tethered surfaces: influence of PEO chain length, grafting density, and temperature. Langmuir 20: 4162-4167.

Oakes JA, Wood AJJ (1986) Infections in surgery. N Engl J Med 315: 1129-1138.

Roosjen A, Busscher HJ, Norde W, Van der Mei HC (2006) Bacterial factors influencing adhesion of Pseudomonas aeruginosa strains to a poly(ethylene oxide) brush. Microbiology 152: 2673-2682.

Saldarriaga Fernández IC, Van der Mei HC, Lochhead MJ, Grainger DW, Busscher HJ (2007) The inhibition of the adhesion of clinically isolated bacterial strains on multicomponent cross-linked poly(ethylene glycol)-based polymer coatings. Biomaterials 28:4105-4112.

Saldarriaga Fernández IC, Van der Mei HC, Metzger S, Grainger DW, Engelsman AF, Nejadnik MR, Busscher HJ (2010) In vitro and in vivo comparisons of staphylococcal biofilm formation on a cross-linked poly(ethylene glycol)-based polymer coating. Acta Biomater 6: 1119-11124.

Schmidt DR, Kao WJ (2007) Monocyte activation in response to polyethylene glycol hydrogels grafted with RGD and PHSRN separated by interpositional spacers of various lengths. J Biomed Mater Res A 83: 617-625

Stewart PS, Costerton JW (2001) Antibiotic resistance of bacteria in biofilms. Lancet 358: 135-138.

Takahashi H, Emoto K, Dubey M, Castner DG, Grainger DW (2008) Imaging surface immobilization chemistry: correlation with cell patterning on non-adhesive hydrogel thin films. Adv Funct Mater 18: 2079-2088.

Wagner VE, Bryers JD (2004) Poly(ethylene glycol)polyacrylate copolymers modified to control adherent monocyte-macrophage physiology: interactions with attaching Staphylococcus epidermidis or Pseudomonas aeruginosa bacteria. J Biomed Mater Res A 69: 79-90.

Xia Z, Triffitt JT (2006) A review on macrophage responses to biomaterials. Biomed Mater 1: R1-9.

\section{Discussion with Reviewers}

Reviewer I: The reactive and inert Optichem ${ }^{\circledR}$ surfaces yielded very similar results for both removal of bacteria and mobility of the macrophages. Did the authors expect a difference to occur between these two surfaces and for what reason was no difference observed?

Authors: Our expectation was that macrophages had a stronger adhesion, resulting in a lower mobility, to the reactive Optichem ${ }^{\circledR}$ than to the inert Optichem ${ }^{\circledR}$ which could result in a lower removal of the bacteria by the macrophages. However, we did not observe any difference in bacterial removal, showing that macrophage interaction depends less on cell matrix adhesive proteins as present in reactive Optichem ${ }^{\circledR}$ than tissue cells.

Reviewer II: Do the authors expect there will be no effects of the surface on macrophage bactericidal function? Do they have reason to expect this? If there might be effects, it would be highly relevant to investigate this in this new test system.

Authors: We know based on literature, that the biomaterial surface may influence (positively or negatively) the macrophage killing ability. However, we did not investigate this in the present study, but we do agree that is it worth and relevant to investigate in a future work.

Reviewer II: The study focuses on one bacterial strain of one bacterial species, namely S. epidermidis 3399. Why do the authors not extend their observations to other relevant bacterial strains / species?

Authors: Staphylococcus epidermidis causes $50 \%$ of the cases of peri-operative infections and for that reason it has been used in the set-up phase of the model, We agree that of course also other strains are involved in perioperative infections that would be interesting to study. 